\title{
Enhancing the aesthetic aspect of the solar systems used as facades for building by designing multi-layer optical coatings
}

\author{
Zainab I. AL-Assadi *, Fawzia Irhayyim AL-Assadi** \\ *Department of Physics, College of Science, Mustansiriyah University, Baghdad, Iraq \\ Zainab I. AL-Assadi :dr.zainab_rhm@uomustansiriyah.edu.iq \\ **Department of Architecture, college of Engineering, Baghdad University, Baghdad, Iraq \\ Fawzia Irhayyim AL-Assadi:fawziaasadi@coeng.uobaghdad.edu.iq \\ **Author for Correspondence: Fawzia Irhayyim AL-Assadi \\ fawziaasadi@coeng.uobaghdad.edu.iq
}

\begin{abstract}
The design of zero-energy buildings can be depending on the effective integration of solar energy systems with building envelopes, where these systems save heat and electricity as well as enhance the aesthetic aspect of the facades. In this paper, the aspects related to the effective integration of buildings with solar energy systems (solar cells and collectors) will be discussed, as well as enhancing the aesthetic aspect of the facades, and since solar energy systems are visible to everyone, their design must adapt to the building structure and the surrounding environment. Solar energy system designers, architects, physicists and other contributors to building energy envelopes must consider the comprehensive concept of it, where buildings are part of the human and social environment and in close relationship with the natural environment, through the use of thin films technology through the design of multi-layers colored optical coatings covering solar panels for building facades. Accordingly, the energy sector should be seen as an area of aesthetic creativity. Two dielectric materials were used, the first is ThF4 with a high refractive index (1.5143) and the second is $\mathrm{LiF}$ with a low refractive index (1.393) and for several odd layers, starting from 3 layers and up to 21 layers and for a thicknesses of a quarter wavelength. The design Air/L/H/Glass was applied by the Mat Lab program for the seven colors of the spectrum, So, the aim of this research is determined in designing colored optical coatings for solar systems that enhance the aesthetic aspect of building facades, as well as generating thermal and electrical energy needed to operate the buildings and to find out which color has the best visible reflectivity and solar transmittance better than the rest of the spectrum, all the results exhibit that yellow color has the higher visible reflectivity and higher merit factor, so it is consider the most efficient color for coloring the solar systems than the rest of colors spectrum. Keywords: Solar systems energy, Aesthetic aspect, Optical coatings, PV, STC
\end{abstract}

\section{1- Introduction}

Energy production and consumption are considered a criterion for the level of civilizational sophistication of nations, that is the level of energy consumption and production indicates the level of economic activity and development in its comprehensive sense. The world has recently become increasingly aware of the great potential of solar energy as an alternative to non-renewable fossil fuel energy. The sun is a clean, unlimited and infinite source of energy, providing for every hour on earth the amount of energy the entire world needs in one year. Solar systems have proven feasibility and their ability to convert their radiation into heat and electricity, and are now largely available at affordable prices. Technological progress in building solar systems has led to transforming the facade of the building into a generator based on renewable energy. The compliant interface is designed to provide 
power generation along with traditional design goals such as aesthetics and environmental control. The use of color solar systems aims to avoid the monotony of black systems by using color optical filters, these systems have lower thermal efficiency than the traditional black type collectors, due to the lower absorption of the collector, however, it is more important for applications in traditional or modern buildings because it gives the facades a more aesthetic aspect. The application of color-reflective solar systems is a new concept, where the increase in the cost of the total solar system is offset by the aesthetic enhancement of the building, Fig.1.

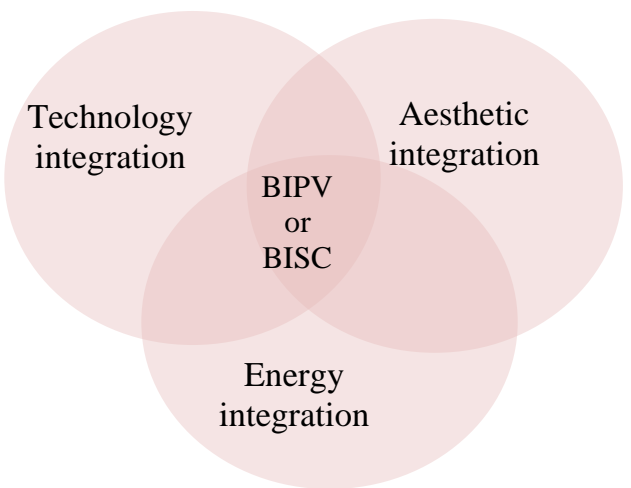

Fig.1. Multilevel Solar systems integration aspect- Researcher

One part of the solar energy of VIS spectrum is invested to make the solar system as a building's facade more beautiful by having other colors, and the other part of the spectrum, which represents most of the energy, will pass in a solar system and will be absorbed and converted into heat in the black surface, with this way the using solar collectors or converting to electrical energy if the solar cell was used and will feed the building as seen in Fig. 2. [5]

The design Air/L/H/Glass was applied in our work by the Mat Lab program for the seven colors of the spectrum using two dielectric materials, the first is ThF4 with a high refractive index (1.5143) and the second is $\mathrm{LiF}$ with a low refractive index (1.393) and for several odd layers (multi- layer thin films), starting from 3 layers and up to 21 layers and for a thickness of a quarter wavelength. All the result show that the values of solar transmittance are close to all colors, ranging between (96-97) \%, meaning that this design has a high solar efficiency for all colors and the yellow color consider is the best for coloring the solar systems.

\section{2- Technologies of solar systems Integration}

The designers paid increasing interest in recent years to the compatibility of technical elements and the aesthetic aspect of the envelope (e.g., façades, frames and roofs) with solar systems. To achieve this aim, technological innovation in solar thermal systems (STC) and photovoltaic (PV) specially today oriented to the possibility to adapt form, dimensions, superficial, color, type of material, finishing, etc. [1] so the reaching "aesthetic environmental compatibility." From a technical and engineering point of view, the utmost possibilities of architectural integration presented by the solar systems are undisputed. Just thinking of individual modules dimensions (absorbers and cells), the pipes' stiffness for transporting hot water in comparison with cables transporting electricity, lastly, the produced energy characteristics: electric energy or thermal energy is intended for consumption in the immediate vicinity of the place where it is produced, while electricity can also be transported over large distance [2]. However, the envelope possibility and the vertical facade generally present well sunny and large surfaces, further more they represent the public shape of the building for which energy issues are sacrificed in favor of architectural consistency. Moreover, existing solar systems were developed as purely technical elements, designed to optimize production, heat gain, and installation [3]. Within the same context, solar 
systems can be either integrated directly into the building elements, subrogation conventional roof or façade cover materials, or constitute independent elements added on façade or roof structure.

In both cases, they each strongly influence the building manifestation. Any device, whether building integrated or not, should offer structural integrity and safeguard from wind, heavy rainwater, and humidity penetration. Solar systems able to ensure interesting architectural integration in the context of the building, raising quality of architecture, must have colors, shape, materials, and size that conform well to the whole composition, creating an aesthetic manifestation harmonized with the building itself [4].

\section{3- Colored solar systems}

One of these methods is by coloring the thermal solar collector is the coloration of the selective absorber slice. By colored absorbers it is aimed to avoid the monotony of the black color solar systems by using absorbers of green, red-brown, blue or other color. These systems are of lower thermal efficiency than usual black type collectors, because of the lower collectors' absorbance, but they are of more interest in applications on traditional or modern buildings [5].

The application of solar systems with colored absorbers is a new concept, where the cost increase of total solar system is balanced by the achieved aesthetic harmony with the building architecture [6].

The difference in energy is balanced by the improvement in aesthetics and this implies the use of proportionate larger collector aperture areas for same energy output, as that of typical black colored collectors Fig.2 [7].

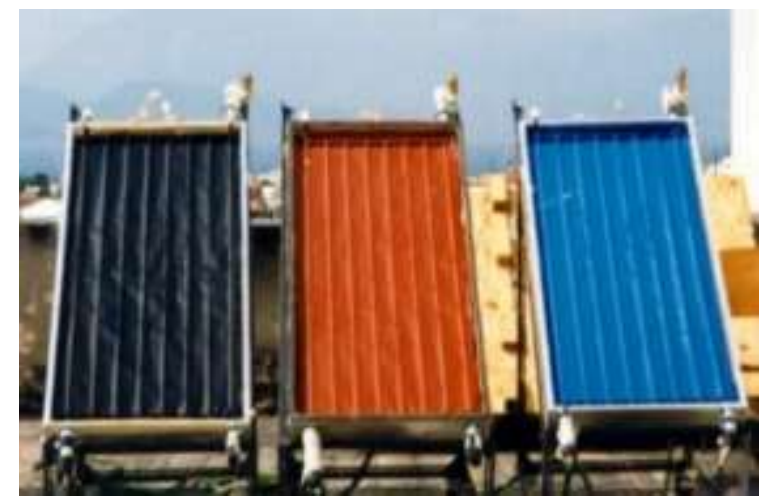

Fig. 2 Colored solar systems which can give new views to buildings [6]

As for the modern method of coloring the solar systems, is by coating the envelope glass which is covering the solar systems by multi- layers optical coating (thin films- multi-layers).

In solar system technology the mass colored glass can cover it; produces modules with semi-transparent systems having different colors and sizes. The solar factor and thermal comfort inside the building can be enhances by designing the color and transparency. New fields of interest in researches were opened up by the developments of these new solar systems, in particular regarding the power output reduction due to the "aesthetics" and the effective energy yield of these systems in real operating conditions (integrated into the different buildings' envelope). Furthermore, probable effects of these facades treatments on the thermal and electrical behavior of the solar technologies must be taken into consideration (e.g. potential mismatch effects, optical reflections, possible localized hot spots, light spectrum, various incidence angles of radiation or temperature difference over the back surface of the modules, etc.) Fig. 3 and its application in buildings. Fig. 4, 5 [8]. 

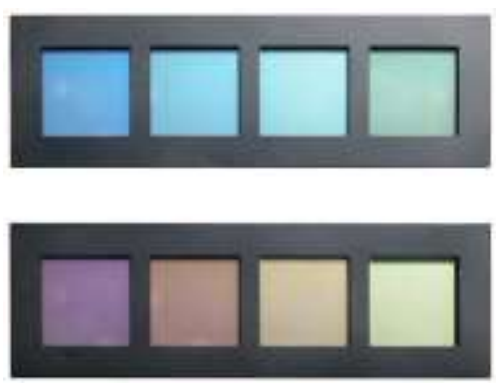

Fig. 3. Different models of the colors of the new solar thermal collectors [8]

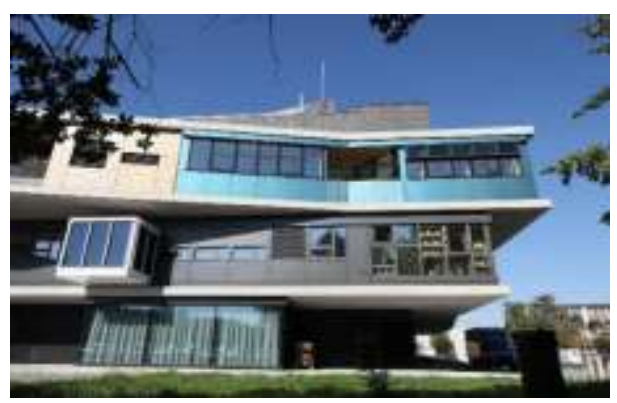

Fig. 4. STC in Nest Solace building, Switzerland [9]

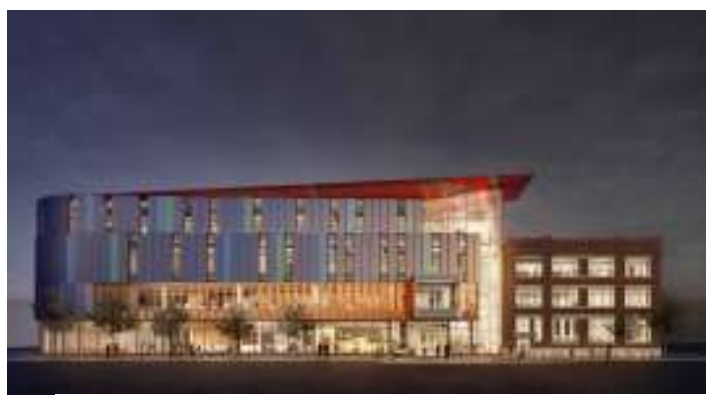

Fig. 5. BIPV in Red river college, Canada [9]

There are two approach it is important to note there: first, a high-technology development has produced modern materials and techniques (fundamentally transporting them from high-tech research fields like physics and optics or materials science), second, techniques which is already used in the building industry have been acclimatized to customize the glass cover of solar systems. It is also important to consider that, in some cases, aspects like design/production building performance, cost-effectiveness, flexibility and production flexibility still remain challenges to be overcome in order to realize high performance in power generation in addition to enhancing the aesthetic aspect. It is significant to highlight is that some above-mentioned customizable solar systems glass has already been implemented in many real buildings. Besides being flexible and thus easy to integrate, the color and appearance of thin film technique will also determine its aesthetic potential. In order to be more compatible towards applications, solar technology has to blend in, as stated earlier. [10].

A colored glaze can be obtained by coating a multi-layer optical thin film, which is within the scope of our work in this research. A colored reflection can be obtained within the visible region and high transmittance in the infrared.

Generally speaking, colored solar systems can be applied in façade, roofing, in addition to shading, balcony glazing, etc. It can Specify a most building of adoption of colored solar systems, these have split into:

1. Public and/or office buildings using colored solar systems façades. Frequently, unique products are wanted on a project to project basis depending on typology and construction.

2. Residential high-rise buildings using colored solar systems façades. For this application, preferably standardized products are required in different colors, with preferring white/greyish colors.

3. Residential low-rise buildings using colored solar systems roofs. The purpose is to hide the functionality of solar systems and thus terracotta color and other roof colors are preferred. [11]. In the next paragraph, we will discuss the thin film technology in some detail.

\section{4- Reflectance, Transmittance and absorbance in Multilayers Thin Films:}

A thin film is a layer or multi-layer (a stack of thin films) of material ranging in thickness from nanometer to several micrometers, (Fig. 6). The thin film layer deposits on the substrate for different purposes like, protecting the substrate, for decorative purposes (changing its appearance), changing the substrates' electrical or optical properties, etc. [12] 


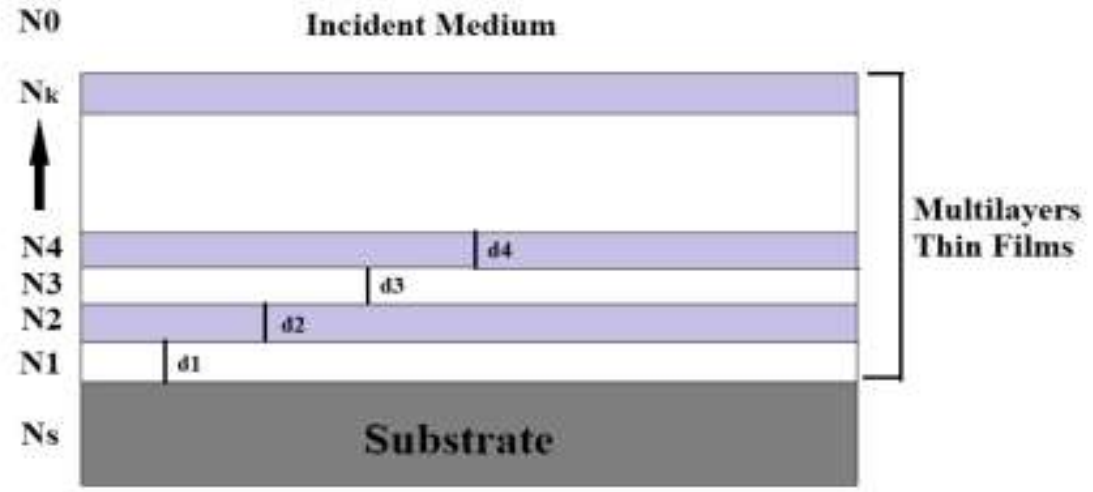

Fig. 6. A multilayer stack of thin films. Researcher

For an assembly (multi-layer) of thin film, the incident medium should be transparent, that is, the optical admittance $\eta_{0}$ must be real. First of all, the net irradiance must be calculating at the exit side of the assembly, its take as the kth interface. We are dealing with the component of irradiance normal to the interfaces

$$
I_{k}=\frac{1}{2} \operatorname{Re}\left(\eta_{m}^{*}\right) E_{k} E_{K}^{*}
$$

$\eta_{\mathrm{m}}$ is the tilted admittance of the substrate, the characteristic matrix of the assembly is

So, the net irradiance at the entrance to the assembly is

$$
I_{1}=\frac{1}{2} \operatorname{Re}\left(X Y^{*}\right) E_{k} E_{k}^{*}
$$

equation (3) represents the irradiance actually entering the assembly, If the incident irradiance be expressed

$$
I_{i}=\frac{\operatorname{Re}\left(X Y^{*}\right) E_{k} E_{k}^{*}}{2(1-r)}
$$
$\mathrm{I}_{\mathrm{i}}$,

Equation (1) represents the irradiance leaving the assembly and entering the substrate and so the transmittance $\mathrm{T}$ is

$$
t=\frac{I_{k}}{I_{i}}=\frac{\operatorname{Re}\left(\eta_{m}\right)(1-r)}{\operatorname{Re}\left(X Y^{*}\right)}
$$

The absorptance (a) in the multilayer is connected with (r) and (t) by

$$
\begin{gathered}
a+r+t=1 \\
a=1-r-t=(1-r)\left(1-\frac{\operatorname{Re}\left(\eta_{m}\right)}{\operatorname{Re}\left(X Y^{*}\right)}\right)
\end{gathered}
$$

So that 
In the absence of absorption in any of the layers it can readily be shown that the above expressions mean $\mathrm{a}=0$ and $\mathrm{t}+\mathrm{r}=1$, for the individual film matrices will have determinants of unity and the product of any number of these matrices will also have a determinant of unity.

$$
\left[\begin{array}{l}
X \\
Y
\end{array}\right]=\left[\begin{array}{cc}
\alpha & i \beta \\
i \gamma & \delta
\end{array}\right]\left[\begin{array}{c}
1 \\
\eta_{m}
\end{array}\right]=\left[\begin{array}{c}
\alpha+i \beta \eta_{m} \\
\delta \eta_{m}+i \gamma
\end{array}\right]
$$

Because there is no absorption, $\alpha, \beta, \gamma$ and $\delta$ are all real. The reflectance of thin film is :

$$
r=\left(\frac{\eta_{0} X-Y}{\eta_{0} X+Y}\right)\left(\frac{\eta_{0} X-Y}{\eta_{0} X+Y}\right)^{*}
$$

And its transmittance is :

$$
t=\frac{4 \eta_{0} \operatorname{Re}\left(\eta_{m}\right)}{\left(\eta_{0} X+Y\right)\left(\eta_{0} X+Y\right)^{*}}
$$

For an assembly of q layers, when the characteristic matrix is the product of the individual matrices taken in the correct order, that is

$$
\begin{gathered}
{\left[\begin{array}{l}
X \\
Y
\end{array}\right]=\left(\prod_{r=1}^{q}\left[\begin{array}{cc}
\cos \delta_{r} & \frac{i \sin \delta_{r}}{\eta_{r}} \\
i \eta_{r} \sin \delta_{r} & \cos \delta_{r}
\end{array}\right]\right)\left[\begin{array}{l}
1 \\
\eta_{s}
\end{array}\right]} \\
{\left[\begin{array}{l}
X \\
Y
\end{array}\right]=W\left[\begin{array}{c}
1 \\
\eta_{s}
\end{array}\right]}
\end{gathered}
$$

Where $W$ is aproduct matrix given by [13],[14]

$$
W=\left[W_{1}\right]\left[W_{2}\right] \ldots\left[W_{a}\right]\left[W_{b}\right]\left[W_{c}\right] \ldots\left[W_{p}\right]\left[W_{q}\right]
$$

\section{Results and Discussion}

In this work, a multi-layer optical interference filter was designed used as a coating for the glass that covering the solar systems (solar cells or solar collectors). This filter consists of two dielectric materials, the first is $\mathrm{ThF}_{4}$ with a high refractive index (1.5143) and the second is $\mathrm{LiF}$ with a low refractive index (1.393) and for several odd layers, starting from 3 layers and up to 21 layers and for a thickness of a quarter wavelength. The design Air/L/H/Glass was applied by the Mat Lab program for the seven colors of the spectrum to find out which color has the best visible reflectivity and solar transmittance better than the rest of the spectrum. The design wavelength was chosen for each color as follows: $\left(\lambda_{\text {violet }}=410\right.$, $\left.\lambda_{\text {Indigo }}=430, \lambda_{\text {Blue }}=465, \lambda_{\text {Green }}=530, \lambda_{\text {Yellow }}=578, \lambda_{\text {Orange }}=603, \lambda_{\text {Red }}=700\right) \mathrm{nm}$. Table 1 shows the results of the visible reflectivity of the seven colors of the spectrum.

Table 1: The values of the visible reflectivity of the seven colors of the spectrum. Researcher

\begin{tabular}{|c|c|c|c|c|c|c|c|}
\hline $\begin{array}{c}\text { Layers } \\
\text { No. }\end{array}$ & $\begin{array}{c}\text { Rvis. } \\
\text { (Violet) }\end{array}$ & $\begin{array}{c}\text { Rvis. } \\
\text { (Indigo) }\end{array}$ & $\begin{array}{c}\text { Rvis. } \\
\text { (Blue) }\end{array}$ & $\begin{array}{c}\text { Rvis. } \\
\text { (Green) }\end{array}$ & $\begin{array}{c}\text { Rvis. } \\
\text { (Yellow) }\end{array}$ & $\begin{array}{c}\text { Rvis. } \\
\text { (Orange) }\end{array}$ & $\begin{array}{c}\text { Rvis. } \\
\text { (Red) }\end{array}$ \\
\hline 3 & 5.7437 & 6.2274 & 6.9702 & 7.7644 & 7.7316 & 7.5054 & $\mathbf{5 . 6 7 5}$ \\
\hline 5 & 3.9217 & 5.1327 & 7.717 & 11.3825 & 11.2821 & 10.2546 & $\mathbf{4 . 5 6 4 5}$ \\
\hline 7 & 3.144 & 3.7017 & 6.9004 & 14.529 & 14.4633 & 12.2537 & $\mathbf{4 . 1 4 7 9}$ \\
\hline
\end{tabular}




\begin{tabular}{|c|c|c|c|c|c|c|c|}
\hline 9 & 4.213 & 4.0607 & 6.2786 & 17.1107 & 17.223 & 13.7897 & $\mathbf{4 . 3 3 4 8}$ \\
\hline 11 & 4.3885 & 4.6938 & 6.3878 & 19.2923 & 19.5934 & 15.1313 & $\mathbf{4 . 3 1 3 9}$ \\
\hline 13 & 4.0047 & 4.6944 & 6.6811 & 21.255 & 21.6455 & 16.4194 & $\mathbf{4 . 3 2 3 2}$ \\
\hline 15 & 3.9744 & 4.6025 & 6.8615 & 23.073 & 23.4578 & 17.6498 & $\mathbf{4 . 3 5 7 8}$ \\
\hline 17 & 4.0164 & 4.576 & 7.0264 & 24.736 & 25.0791 & 18.7692 & $\mathbf{4 . 3 5 8 8}$ \\
\hline 19 & 4.067 & 4.5403 & 7.2032 & 26.2187 & 26.5324 & 19.7496 & $\mathbf{4 . 3 8 1 1}$ \\
\hline 21 & 4.0983 & 4.5673 & 7.3349 & 27.5187 & 27.8274 & 20.5989 & $\mathbf{4 . 3 9 0 3}$ \\
\hline
\end{tabular}

The results show that the yellow, green, and orange colors have the best visible reflectivity, and the best of them is the yellow color, as the visible reflectivity increases by increasing the number of layers until it reaches (27.82) at the 21 layer as shown in the Fig. 7.

Fig. 7 The relationship between the visible reflectance and the layer's number. Researcher

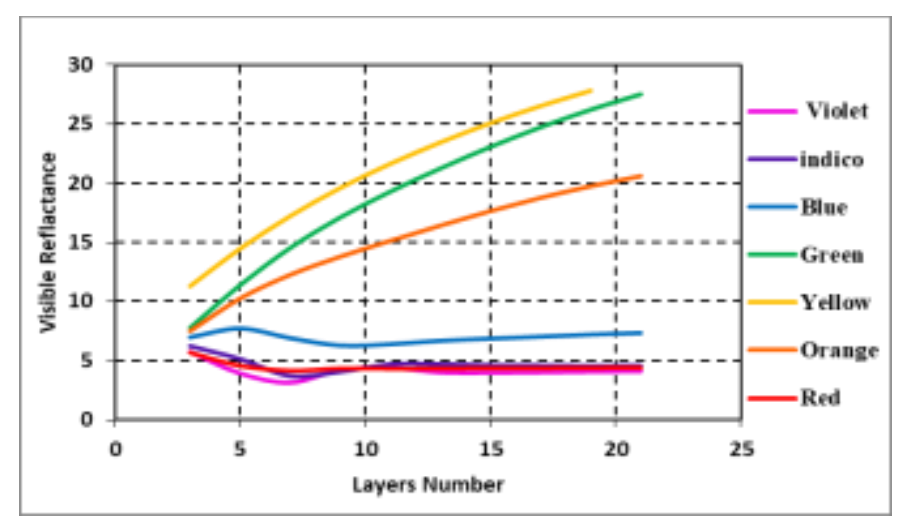

As for the solar transmittance, it is noted from the Table2 that its values are close to all colors, ranging between (96-97)\%, meaning that this design has a high solar efficiency for all colors. Relationship between solar transmittance and the number of layers for the seven colors of the spectrum shown in Fig.8.

Table 2: The values of the solar transmittance of the seven colors of the spectrum. Researcher

\begin{tabular}{|c|c|c|c|c|c|c|c|}
\hline $\begin{array}{c}\text { Layers } \\
\text { No. }\end{array}$ & $\begin{array}{c}\text { Tsol. } \\
\text { (Violet) }\end{array}$ & $\begin{array}{c}\text { Tsol. } \\
\text { (Indigo) }\end{array}$ & $\begin{array}{c}\text { Tsol. } \\
\text { (Blue) }\end{array}$ & $\begin{array}{c}\text { Tsol. } \\
\text { (Green) }\end{array}$ & $\begin{array}{c}\text { Tsol. } \\
\text { (Yellow) }\end{array}$ & $\begin{array}{c}\text { Tsol. } \\
\text { (Orange) }\end{array}$ & $\begin{array}{c}\text { Tsol. } \\
\text { (Red) }\end{array}$ \\
\hline 3 & 96.3587 & 96.4047 & 96.4874 & 96.6455 & 96.7631 & 96.8237 & $\mathbf{9 7 . 0 4 6 7}$ \\
\hline 5 & 97.0813 & 97.1416 & 97.2293 & 97.3205 & 97.3208 & 97.2973 & $\mathbf{9 7 . 0 6 2 3}$ \\
\hline 7 & 97.2894 & 97.2517 & 97.1398 & 96.8072 & 96.5027 & 96.3413 & $\mathbf{9 5 . 8 3 5 3}$ \\
\hline 9 & 96.7753 & 96.6152 & 96.3306 & 95.9029 & 95.7679 & 95.7761 & $\mathbf{9 6 . 2 8 0 1}$ \\
\hline 11 & 96.049 & 95.9173 & 95.7949 & 95.9824 & 96.4009 & 96.6591 & $\mathbf{9 7 . 3 4 5 6}$ \\
\hline 13 & 95.8129 & 95.8895 & 96.1741 & 96.9264 & 97.2966 & 97.3322 & $\mathbf{9 6 . 4 8 9 2}$ \\
\hline 15 & 96.2905 & 96.5605 & 97.0155 & 97.2953 & 96.8602 & 96.5086 & $\mathbf{9 5 . 7 5 7 2}$ \\
\hline 17 & 97.0271 & 97.2281 & 97.2916 & 96.5154 & 95.8731 & 95.7601 & $\mathbf{9 6 . 8 8 0 9}$ \\
\hline 19 & 97.3031 & 97.1749 & 96.6584 & 95.7923 & 96.0715 & 96.4896 & $\mathbf{9 7 . 1 9 5 8}$ \\
\hline 21 & 96.843 & 96.4587 & 95.8999 & 96.2185 & 97.11 & 97.3301 & $\mathbf{9 5 . 9 4 8 3}$ \\
\hline
\end{tabular}


Fig. 8. shows the relationship between solar transmittance and the number of layers for the seven colors of the spectrum. Researcher

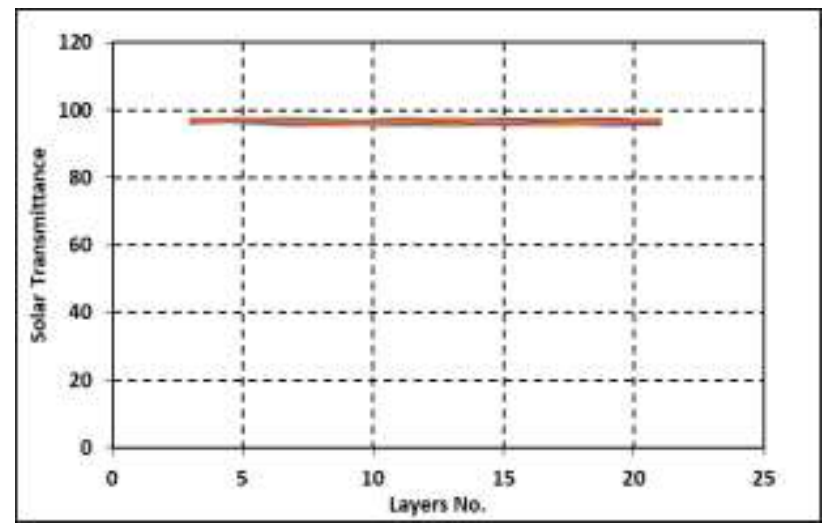

In the other hand, it is noted from the Table 3 the solar reflectivity, which represents the amount of loss in the solar systems has small amount for the seven colors of spectrum, as it ranges between (3-4) \% as shown in the Fig. 9.

Table 3: The values of the solar reflectivity of the seven colors of the spectrum. Researcher

\begin{tabular}{|c|c|c|c|c|c|c|c|}
\hline $\begin{array}{c}\text { Layers } \\
\text { No. }\end{array}$ & $\begin{array}{c}\text { RSol. } \\
\text { (Violet) }\end{array}$ & $\begin{array}{c}\text { RSol. } \\
\text { (Indigo) }\end{array}$ & $\begin{array}{c}\text { RSol. } \\
\text { (Blue) }\end{array}$ & $\begin{array}{c}\text { RSol. } \\
\text { (Green) }\end{array}$ & $\begin{array}{c}\text { RSol. } \\
\text { (Yellow) }\end{array}$ & $\begin{array}{c}\text { RSol. } \\
\text { (Orange) }\end{array}$ & $\begin{array}{c}\text { RSol. } \\
\text { (Red) }\end{array}$ \\
\hline 3 & 3.6413 & 3.5953 & 3.5126 & 3.3545 & 3.2369 & 3.1763 & 2.9533 \\
\hline 5 & 2.9187 & 2.8584 & 2.7707 & 2.6795 & 2.6792 & 2.7027 & 2.9377 \\
\hline 7 & 2.7106 & 2.7483 & 2.8602 & 3.1928 & 3.4973 & 3.6587 & 4.1647 \\
\hline 9 & 3.2247 & 3.3848 & 3.6694 & 4.0971 & 4.2321 & 4.2239 & 3.7199 \\
\hline 11 & 3.951 & 4.0827 & 4.2051 & 4.0176 & 3.5991 & 3.3409 & 2.6544 \\
\hline 13 & 4.1871 & 4.1105 & 3.8259 & 3.0736 & 2.7034 & 2.6678 & 3.5108 \\
\hline 15 & 3.7095 & 3.4395 & 2.9845 & 2.7047 & 3.1398 & 3.4914 & 4.2428 \\
\hline 17 & 2.9729 & 2.7719 & 2.7084 & 3.4846 & 4.1269 & 4.2399 & 3.1191 \\
\hline 19 & 2.6969 & 2.8251 & 3.3416 & 4.2077 & 3.9285 & 3.5104 & 2.8042 \\
\hline 21 & 3.157 & 3.5413 & 4.1001 & 3.7815 & 2.89 & 2.6699 & 4.0517 \\
\hline
\end{tabular}

Fig.9. The relationship between the solar reflectivity and the layer's number.

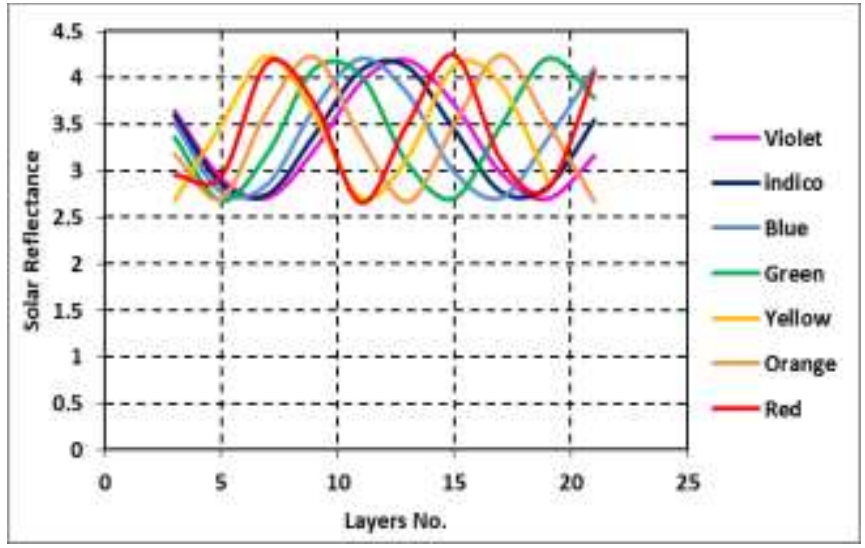


As for the coloring efficiency or the merit factor (M), whose values are shown in the Table 4, which shows that yellow is the most efficient color for coloring the solar systems, followed by green and then orange, as for the rest of the violet, indigo, blue and red colors, they are considered to have low coloring efficiency, see Fig. 10.

Table 4: The values of merit factor of the seven colors of the spectrum. Researcher

\begin{tabular}{|c|c|c|c|c|c|c|c|}
\hline $\begin{array}{c}\text { Layers } \\
\text { No. }\end{array}$ & $\begin{array}{c}\text { Merit } \\
\text { Factor } \\
\text { (Violet) }\end{array}$ & $\begin{array}{c}\text { Merit } \\
\text { Factor } \\
\text { (Indigo) }\end{array}$ & $\begin{array}{c}\text { Merit } \\
\text { Factor } \\
\text { (Blue) }\end{array}$ & $\begin{array}{c}\text { Merit } \\
\text { Factor } \\
\text { (Green) }\end{array}$ & $\begin{array}{c}\text { Merit } \\
\text { Factor } \\
\text { (Yellow) }\end{array}$ & $\begin{array}{c}\text { Merit } \\
\text { Factor } \\
\text { (Orange) }\end{array}$ & $\begin{array}{c}\text { Merit } \\
\text { Factor } \\
\text { (Red) }\end{array}$ \\
\hline 3 & 1.5774 & 1.7321 & 1.9843 & 2.3146 & 2.3886 & 2.363 & 1.9216 \\
\hline 5 & 1.3436 & 1.7957 & 2.7852 & 4.248 & 4.2109 & 3.7943 & 1.5538 \\
\hline 7 & 2.9187 & 1.3469 & 2.4125 & 4.5506 & 4.1356 & 3.3492 & 0.996 \\
\hline 9 & 1.3065 & 1.1997 & 1.711 & 4.1763 & 4.0696 & 3.2647 & 1.1653 \\
\hline 11 & 1.1107 & 1.1497 & 1.5191 & 4.8019 & 5.444 & 4.5291 & 1.6252 \\
\hline 13 & 0.9564 & 1.1421 & 1.7463 & 6.9153 & 8.0068 & 6.1546 & 1.2314 \\
\hline 15 & 1.0714 & 1.3381 & 2.299 & 8.5309 & 7.471 & 5.0552 & 1.0271 \\
\hline 17 & 1.351 & 1.6509 & 2.5943 & 7.0986 & 6.077 & 4.4268 & 1.3975 \\
\hline 19 & 1.508 & 1.6071 & 2.1557 & 6.2311 & 6.7539 & 5.626 & 1.5623 \\
\hline 21 & 1.2982 & 1.2897 & 1.7889 & 7.2772 & 9.6288 & 7.7152 & 1.0836 \\
\hline
\end{tabular}

Fig. 10. The relationship between merit factor and the layer's number. Researcher

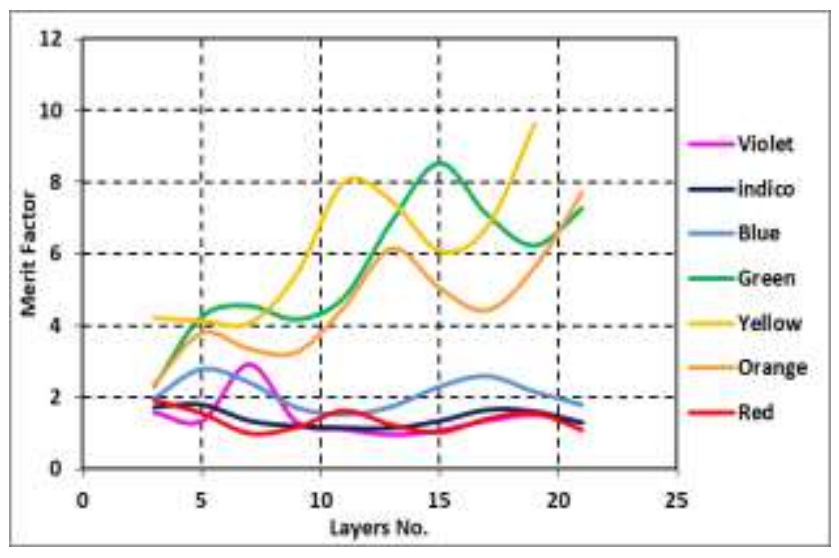

\section{Conclusion}

1- Yellow color has the higher visible reflectivity and higher merit factor, so it is considering the most efficient color for coloring the solar systems than the rest of colors spectrum.

2- The values of solar transmittance are close to all colors, ranging between (96-97)\%, meaning that this design has a high solar efficiency for all colors.

3- The loss in solar systems has small amount for the seven colors of spectrum which represented by solar reflectivity, as it ranges between (3-4) \% .

4- Coloring the solar systems used as facades for building is the method for enhancing the aesthetic aspect of the buildings, so the physicist designs and manufactures multi-layer color optical coatings which has higher coloring efficiencies and lower solar losses, and choosing the color of the building is a task for the architect. 
5- Understanding the basics of solar design strategies and architectural applications, the principles of these systems and integration, and the various economic and non-economic benefit factors means the great success of the project due to its multifunctional nature. These technologies add a new dimension to the fields of design and construction, as well as replacing traditional building envelope materials. These systems are a natural source of energy generated through the grid.

\section{References}

[1] Hestnes, A.G. Building integration of solar energy systems. Sol. Energy 1999, 67, 181-187. [Google Scholar] [CrossRef]

[2] Munari Probst, M.C.; Roecker, C. Towards an improved architectural quality of building integrated solar thermal systems (BIST). Sol. Energy 2007, 81, 1104-11169. [Google Scholar] [CrossRef] .

[3] Arpino, F.; Cortellessa, G.; Frattolillo, A. Experimental and numerical assessment of photovoltaic collector's performance dependence on frame size and installation technique. Sol. Energy 2015, 118, 719. [Google Scholar] [CrossRef]

[4] Buonomano, A.; Forzano, C.; Kalogirou, S.A.; Palombo, A. Building-façade integrated solar thermal collectors: Energy-economic performance and indoor comfort simulation model of a water based prototype for heating, cooling, and DHW production. Renew. Energy 2019, 137, 20-36. [Google Scholar] [CrossRef].

[5] Probst, \& et al, "Bringing colores to solar collectors: a contribution to an increased building "integrability", Colore \& Light in Architectecture. Venice, Italy, 2010.

[6] Tripanagnostopoulos, et al, "Solar collectors with colored absorbers. Solar Energy", 2000; 68: 343356.

[7] Dierick, Maurits, "Aesthetic PV Integration Aesthetically Appealing PV Integration \& Technology", Campus Geel, Kleinhoefstraat 4, BE-2440 Geel, 2017, p. 42.

[8] Saretta, Erika, and et al, "BIPV Meets Customizable Glass: A Dialogue between Energy Efficiency and Aesthetics", 35th EU PVSEC ,2018, Brussels, 6AO.8.2.; doi: 10.4229/35thEUPVSEC201820186AO.8.2.

[9] https://www.swissinso.com/projects

[10] Saretta, Erika and et al, "Active BIPV Glass Facades: Current Trends of Innovation"; GPD Glass Performance Days 2017 - Conference Proceedings, pp.2-7; https://www.glassonweb.com/article/activebipv-glass-facades-current-trends-innovation.8/9/2021

[11] IEA SHC Task 59 (2017-2021); "Renovating Historic Buildings Towards Zero Energy"; http://task59.iea-shc.org.5/9/2021

[12] Samira Naghdi, Thin films- definition, deposition techniques, and applications, February 2021, Conference: Bu-Ali Sina university Weekly webinar.

[13] H A Macleod, Thin-Film Optical Filters, THIRD EDITION, Thin Film Center Inc. Tucson, Arizona and, University of Arizona, 2001.

[14] Filiz KARAÖMERLIOĞLLU, (Optical Properties of Multilayer Antireflection Coating System on A Ferroelectric Base), University of Cukurova Institute of Natural and Applied Sciences, Adana, 